\title{
Does free distribution of ITN affect its usage? A survey among mothers/caregivers in Ilaro Ogun State, Nigeria
}

\author{
Adekanmi Adewole ${ }^{1}$, Foluso Faparusi ${ }^{2}$, Funmilayo Falilat Alli $^{3}$ \\ ${ }^{1}$ Lecturer, ${ }^{2}$ Lecturer, ${ }^{3}$ Assistant Chief Technologist, Department of Science Laboratory Technology, \\ Federal Polytechnic, Ilaro, Ogun State, Nigeria.
}

\section{To the Editor}

Malaria is a growing public health problem in Africa. Each year, 300-500 million people worldwide suffer from the disease and it causes over one million deaths, most of which affect children under 5 years old in sub-Saharan Africa. ${ }^{1}$ In Africa, one out of 20 children is likely to die of a malariarelated illness before their fifth birthday. ${ }^{2}$ The cheapest malaria drug, chloroquine, is rapidly losing its clinical effectiveness in almost all endemic countries and strains of malaria have developed resistance to the four leading antimalarial drugs. ${ }^{3}$ Efforts have been undertaken to fight against rolling back malaria and one of these is the use of insecticidetreated nets (ITNs) in many African countries, especially by the more vulnerable group pregnant women and children. ${ }^{4}$ Consistent use of insecticide treated nets and curtains have been shown to be effective in reducing malaria. Current data indicates that insecticide treated nets (ITNs) use can prevent $19 \%$ of child deaths from all causes, with some countryspecific studies in Africa suggesting that as much as $42 \%$ of all cause mortality among children under five can be averted. ${ }^{5,6}$ However, it has been shown that ITN use is low among the segments of the population at greatest risk of malaria even though there are efforts to distribute it free by donor agencies and others stakeholders. This study was conducted in Ilaro, a rural-urban town and the headquarters of Yewa South Local Government Area of Ogun State in Nigeria, with an aim to assess the relationship between free ITN distribution and its usage in the community.

The study utilized a descriptive cross-sectional design and 310 people were selected using a multistage sampling procedure. In the first stage, the study area was divided into ten clusters using geographical features and map sketches obtained from the local town planning department. In the second stage, four of these ten clusters were randomly selected and house listing was done. In the third stage an eligible respondent was selected from each household through balloting for eligible caregivers-child pairs. An eligible respondent/caregiver was either a father or mother having a child aged between $0-5$ years old. Where two parents were met, the mother was interviewed. Verbal consent was sought from each respondent and the purpose of the data collection was fully explained.

The use of ITNs among the study population and their sociodemographic variables was shown in Table 1 . The result indicated that free distribution of ITN does not translate to its usage in most cases. Despite the fact that majority of the respondents $(94.5 \%)$ had good knowledge of malaria transmission and symptoms, and approximately $66 \%$ of the respondents have an ITN at home (obtained through the free distribution exercise by Federal Ministry of Health/UNICEF), only $34 \%$ of the respondents were using ITNs regularly during night. When asked about the various methods of protection from mosquito bites, respondents mentioned mosquito spray/repellents $(76.8 \%)$, prophylaxis medication (17.4\%), burning of leaves to repel mosquito $(12.3 \%)$ and use of ITNs (31.3\%). The important reasons for not using ITNs include the inconveniency of its usage $(63 \%)$, the irritable odor of insecticide $(30 \%)$ and the difficulty of finding a suitable place to hang it (5\%). This was confirmed by some authors, who reported that sleeping arrangement and availability of suitable location to hang the net was a hindrance to the use of ITNs. ${ }^{8,9}$ The findings indicate a need for technological improvement in making ITNs attractive to the consumers. The preference of indoor residual spray to ITNs in malaria endemic countries is common $^{10}$ and has became popular due to a mass campaign and a more widespread awareness in the community. A similar approach can be taken to promote the use of ITNs but free distribution without adequate and appropriate information, as well as behavioral change for those in need of protection will not produce expected results.'

Substantial reduction in malaria related illness can be reduced by the use of ITN which may, in turn, reduce pressure on limited national healthcare budgets. ${ }^{1,4}$ Another major constraint of using ITNs is the cost, which discourages access and utilization among the lower socioeconomic segment of the community, ${ }^{4,11}$ Free distribution and its effective monitoring procedures should be part of the programs. Above all, the need for educational and behavioral change campaigns to promote proper usage by vulnerable population is crucial.

Correspondence: Adekanmi Adewole, Lecturer, Department of Science Laboratory Technology, Federal Polytechnic, Ilaro, Ogun State, Nigeria.E mail: adewolejak@yahoo.com. 
Table 1: Socio-demographic variables of the respondents and use of ITNs

\begin{tabular}{|l|c|c|c|}
\hline Variables & \multicolumn{2}{|c|}{ Use of ITN } & $\begin{array}{c}\text { Statistical } \\
\text { indices }\end{array}$ \\
\hline Age & Yes & No & Chi-square \\
\hline $19-29$ & $38(37.6 \%)$ & $63(62.4 \%)$ & $\mathrm{P}=0.639$ \\
\hline $30-39$ & $48(41.7 \%)$ & $67(58.3 \%)$ & \\
\hline $40-49$ & $34(48.6 \%)$ & $36(51.4 \%)$ & \\
\hline$>50$ & $7(29.2 \%)$ & $17(70.8 \%)$ & \\
\hline Marital Status* & & & \\
\hline Married & $105(40.2 \%)$ & $156(59.8 \%)$ & $\mathrm{P}=0.000$ \\
\hline Not married & $9(52.9 \%$ & $8(47.1 \%)$ & \\
\hline Divorced & $5(33.3 \%)$ & $10(66.7 \%)$ & \\
\hline Widow/ & $8(47.1 \%)$ & $9(52.9 \%)$ & \\
\hline widower & & & \\
\hline Education* & & & \\
\hline Primary & $2(8.7 \%)$ & $21(91.3 \%)$ & $\mathrm{P}=0.012$ \\
\hline $\begin{array}{l}\text { Junior } \\
\text { secondary }\end{array}$ & $35(40.7 \%)$ & $51(59.3 \%)$ & \\
\hline Senior & $14(35.9 \%)$ & $25(64.1 \%)$ & \\
secondary & $27(42.2 \%)$ & $37(57.8 \%)$ & \\
\hline Tertiary & $46(48.9 \%)$ & $48(51.1 \%)$ & \\
\hline Others & $3(75 \%)$ & $1(25 \%)$ & \\
\hline Income* & & & \\
\hline Trading & $50(31.6 \%)$ & $108(68.4 \%)$ & $\mathrm{P}=0.000$ \\
\hline Artisan & $31(22.2 \%)$ & $14(77.8 \%)$ & \\
\hline Farming & $4(22.2 \%)$ & $14(77.8 \%)$ & \\
\hline Teaching & $11(73.3 \%)$ & $4(26.7 \%)$ & \\
\hline Civil servant & $20(80.0 \%)$ & $5(20.0 \%)$ & \\
\hline Not employed & $11(37.9 \%)$ & $18(62.1 \%)$ & \\
\hline Signficant & & & \\
\hline
\end{tabular}

*Significant

\section{References}

1. WHO. The Global Malaria Action Plan. For a malaria free world. Geneva: World Health Organization, 2008.
2. WHO. The World Health Report. Geneva: World Health Organization, 1999.

3. WHO. Roll Back Malaria fact sheet: Malaria - A global crisis. Geneva: World Health Organization, 2000.

4. Aliyu AA, Alti-Mu'azu M. Insecticide-treated nets usage and malaria episodes among boarding students in Zaria, Northern Nigeria. Ann Afr Med 2009;8:85-9.

5. D'Alessandro U, Olaleye B, McGuire W et al. Mortality and morbidity from malaria in Gambian Children after introduction of an impregnated bed net program. Lancet 1995;345:479-83.

6. National Population Commission (NPC) [Nigeria] and ICF Macro. Nigeria Demographic and Health Survey 2008. Abuja, Nigeria: National Population Commission and ICF Macro, 2009.

7. Malaria Consortium. Coverage and use of insecticide treated nets in Kano. http://www.malariaconsortium.org/ news-centre/coverage-and-use-of-insecticide-treatednets-in-kano.htm (accessed 31 Dec 2011)

8. Renne EP, Kirby K, Akkineni R. Bednet use and malaria knowledge in Zaria City, Nigeria. J Int Inst 2008;15:5.

9. Iwashita H, Gabriel D, Kyoko F et al. Sleeping arrangement and house structure affects bed-net use in villages along Lake Victoria. Malar J 2010;9:176.

10. Onwujekwe O, Reginald C, Okonkwo P. Economic burden of malaria on Households versus that of all other illness episodes: A study in five malaria holoendemic Nigeria communities. Health Policy 2000;54: 143-59.

11. Baume CA, Celeste M. Gains in awareness, ownership and use of insecticide treated nets in Nigeria, Senegal, Uganda and Zambia. Malar J 2008;7:153. 